\title{
From landscape affordances to landscape connectivity: contextualizing an archaeology of human ecology
}

\author{
Michael Kempf ${ }^{1,2}$ (D)
}

Received: 27 April 2020 / Accepted: 10 July 2020 / Published online: 20 July 2020

(C) The Author(s) 2020

\begin{abstract}
To understand the connectivity in human-landscape ecosystems, a multidirectional concept of landscape transformation, sociocultural development, and human response cycles needs to be considered. In this context, societal decision-making is controlled by the ecosystem's functionality; the human perception, experience, memory, and tradition; and the individual configuration of landscape components: a conceptual framework that is herein referred to as landscape affordances. In contrast to defining environmental components as passive resources, the concept of landscape affordances entails dynamic and processual feedbacks of an individual and the environment in the moment of mutual interaction - thus actively integrating human ingenuity in the production of landscapes, biological processes, and sociocultural patterns. This article contextualizes the concepts of landscape affordances and functional ecosystem connectivity to evaluate human behavioural patterning and the production of landscapes in a methodological landscape archaeological approach.
\end{abstract}

Keywords Human ecology $\cdot$ Resilience $\cdot$ Vulnerability $\cdot$ Resource assemblages $\cdot$ Perception $\cdot$ Landscape archaeology

\section{Introduction}

In 1994, Thomas Greider and Lorraine Garkovich published an essay on the social construction of landscape and the environment in which they argue that sociocultural phenomena transform the physical environment into landscapes as part of the process of social self-definition (Greider and Garkovich 1994). According to Greider and Garkovich, the natural world is meaningless to individuals because meaning is not inherent in the nature of things. Furthermore, the "symbols and meanings that comprise landscapes reflect what people in cultural groups define to be proper and improper relationships among themselves and between themselves and the physical environment" (Greider and Garkovich 1994, p. 2). This is a delicate statement that has met much opposition. Taylor, for example, argues that landscapes are human-made

Michael Kempf

kempf@phil.muni.cz; michael.kempf@archaeologie.uni-freiburg.de

1 Department of Archaeology and Museology, Masaryk University, Brno, Czech Republic

2 Physical Geography, Institute of Environmental Social Science and Geography, Faculty of Environment and Natural Resources, University of Freiburg, Schreiberstr. 20, 79085 Freiburg, Germany artefacts of cultural values and can rather be seen as continuous processes of environmental reorganization than expression of deeper sense or agency inherent in objects that are distributed in some way in space (Stedman 2003; Taylor 2012). In turn, the scale of the "perceptible realm" (Gobster et al. 2007) of landscapes at which humans intentionally alter and constantly modify their immediately perceived surroundings has a direct influence on the environment. Certain parts of the environment are perceived differently than others, which leads to mental and eventually physical categorization of the available space. Whether these classifications are caused by "aesthetics" of the landscape (e.g. good/bad, pretty/ugly, welcoming/threatening) (Gobster et al. 2007) or by shared individual and group experiences, ideas, and traditions (Gramsch 1996) is debated. Moreover, cultural transition between different social groups organizes communication networks and movement corridors disregarding environmental prerequisites (Furholt 2018; Llobera 1996; Müller 2005). As a result, all landscapes are dynamic: organisms change habitats and adapt to altered ecological conditions; social and cultural group developments affect adjacent communities through transport of material culture, and technological and economic enhancements spread along communication networks and movement corridors. Most of these changes occur over the longue durée-leading to a continuous sedimentation of cultural 
landscapes. However, frequent environmental crisis and sociocultural turmoil generate significant breaks in the stratification. Landscapes are thus considered as human-made assemblages with process-oriented and event-driven layers put on top of each other.

The intense environmental interaction and the cultural and social imprints of premodern societies represent an important link in understanding the development of present-day landscapes. In this context, this article addresses the methodological integration of the concepts of landscape affordances (Gibson 1979) and landscape connectivity (Taylor et al. 1993; Taylor et al. 2006) in archaeology, and develops a conceptual approach to redefine the scale of activity ranges and patterning of human behaviour in the landscape.

\section{Methodology}

This section introduces the concepts, which form the basis of the methodological approach of this paper. The approaches behind the terms landscape affordance and landscape connectivity are presented in detail. Emerging from objectbased psychology and ecosystem functionality, the integration of landscape affordance and connectivity represents a novel concept in understanding decision-making, governance, and resilience of past human groups and individuals in their environmental settings.

\section{Contextualizing landscape affordances}

The neologism affordance, first introduced into psychology by James Gibson in the late 1970s, describes the phenomenon of propositions emanating from objects within a specific environment (Gibson 1979; Jung 2018; Loveland 1991). Affordances are not (meta)physical properties but rather empirical meanings that are in some way arranged in space (Jung 2018). However, to understand the concept of affordances, one needs to discover fluctuations in the physical conditions of the environmental system that surrounds the object and the observer. Gibson refers to the properties of affordances as unchangeable in contrast to the constant variability of their receptors: "The affordance of something does not change as the need of the observer changes" (Gibson 1979). That stands in contrast to the view of material affordances proposed by Carl Knappett (2004) who assumes changing affordances in relation to the situation in which they are found (Knappett 2004). If there is a constant tie between space and observer, then it is negligible which component in the system changes. A modification would ultimately lead to a modified system with different environmental conditions that require adaptation to the new situation. Gibson's affordances are not mere natural appearances but rather a complex interplay of the experience, the idea, and the knowledge of a specific environmental prototype that enables the interaction between the surrounding and the observer. In contrast to defining the components of the environment as passive resources, the concept of landscape affordances aligns dynamic and processual feedbacks with an individual's behaviour in the moment of mutual interaction (Gillings 2009). Human activity in landscapes, however, is limited by the individual's vulnerability to natural phenomena and the capability to overcome sitespecific limitations: a river localizes an individual's activity range but simultaneously triggers the intention to cross it. The physical properties of the immediate landscape generate substantial affordances that are much more essentially perceived than material-based object affordances. Individuals are literally involved in the production of landscape through their personal adaptability towards environmental prerequisites and impacts.

\section{Decision-making environments}

Finding a meaningful definition of the environment requires an anthropocentric notion of how human life is situated in a broader relationship to the biosphere, ecology, and physical reality (Alexander 2009). It is mostly about where to locate human behaviour within a conceptual framework of humanenvironmental interactions and whether a society constantly adapts to the environment or the environment causes societal reaction to rapid changes in the ecological balances (Ellis 2015; Fazey et al. 2010; Harden 2012; Head 2010). However, sociocultural evolution is a process without a clearly defined goal. All anthroecological theories of human behaviour transforming the anthropogenic biosphere need to be aware of past human testing strategies on how the ecological systems could have been working at specific moments in time - a rather palaeoecological "trial and error" of past societies (Ellis 2015).

As mentioned earlier, a heavy theoretical burden is placed on the perception of the environment. Does an individual perceive their surroundings merely through the physical transport of radiation that causes a specific sensation and finally an informative perception? Or is there a direct meaning in the environment that is continuously received by the individual in the immediate moment of confrontation (Chemero 2003; Ingold 2000)? Gibson's environment and the affordances in there consist of possibilities that enable an individual's behaviour (Bruineberg et al. 2019; Withagen et al. 2012; Withagen and Chemero 2009). Hence, landscape affordances are non-material, relative environmental properties that interact with and are perceived through the individual (Heras-Escribano and de Pinedo-García 2017). As HerasEscribano and de Pinedo-García (2017) put it, there is no clear distinction between the objective (agent-independent) and the subjective (agent-dependent) characters of affordances. The organism-environment system complements itself through mutual affordances of the ecological parameters within the 
organism's habitat (Gibson 1979; Heras-Escribano and de Pinedo-García 2017; Rietveld and Kiverstein 2014). Therefore, affordances not only are potential decision arrangements in the life track of organisms but also can generate agglomerations of attractions or repulsions that influence the agent's behaviour and thus make an impact on the composition of future affordances (Withagen et al. 2017). Finally, affordance sequences were created that accompany the individual's decision-making. Due to the fact that decision-making directly affects the individual's social environment and his/her descendants, the affordance arrangements are passed on over time and space. Environmental palimpsests were formed that contain past, present, and potential future affordance assemblages within a continuously reshaping, situational, and performative landscape.

\section{Scales of landscapes}

According to the definition by Marquardt and Crumley, landscapes are spatial descriptions of human-environment interactions (Crumley 2016; Crumley and Marquardt 1990; Marquardt and Crumley 1987). That means that landscapes are understood as the most appropriate spatial scale to detect functional ecological networks within terrestrial ecosystems (Baguette et al. 2013). In this functional context, Butzer (1982) refers to the concept of niche construction in ecology and the occupation of a specific physical space by an organism which is centred around a resource (Butzer 1982, p. 15). The "landscape scale", as determined by Meyer and Crumley (2011), is the spatial interface where "human activity and biophysical systems interact" and consequently archaeological records are available (Meyer and Crumley 2011). But are landscapes mere spatial relations of objects or resources placed in the environment? The ambiguity of the term "landscape" is rooted in the divergence of the concepts of biogeography and landscape ecology: Biogeography defines the landscape as a spatio-temporal level of organization with specific geomorphology and climate (Baguette et al. 2013; Hanson et al. 2012; Lomolino et al. 2015). Landscape ecology approaches the organism's distribution, its personal perception of the surroundings, the extent of its individual activity sphere, and how these parameters are affected by the structure of the landscape (Baguette et al. 2013; Gurrutxaga et al. 2010; Kent 2007; Kupfer 2012; Schaich et al. 2010). Consequently, spatial scales are variable and landscapes should rather be seen as fuzzy geometries where heterogeneous patterns generate processes (Cushman et al. 2010; Kent 2007; McGarigal and Cushman 2009).

The potential of a landscape to provide resources is very closely tied to the configuration and the properties of the respective resource patches distributed in space. This ecological connectivity model is well advanced and allows to understand the spatial arrangements and movement patterns, which link human behaviour and landscape elements (O'Farrell and Anderson 2010; Watson et al. 2017). To describe the behavioural patterns behind the structured landscape, Taylor et al. (1993) introduced the basic concept of the so-called landscape connectivity. According to the authors, landscape connectivity emerges from the interaction between a behavioural process (movement) and the (physical) landscape structure. Two different kinds of connectivity can be distinguished: a structural landscape connectivity that focuses only on (static) physical relationships among and between resource or habitat patches and a functional landscape connectivity that takes into account the dynamically developing characteristics of the physical landscape and the multidirectional and situational movement flows of the organisms (Taylor et al. 1993; Taylor et al. 2006; Watson et al. 2017). Landscape connectivity is a function of both, as it depends primarily on movement patterns that are strongly connected to terrain permeability and the composition of available resource patches (Fig. 1). Hence, landscape connectivity defines the degree to which a given landscape enables movement among these patches (Baguette et al. 2013; Kupfer 1995; Taylor et al. 1993; Tischendorf and Fahrig 2000b). These habitat patches are in the process of continuous development and hence force the organism to constantly adapt to the situational landscape structures. In this context, the scalar approaches of landscapes are determined by the movement scales of the organism and the size and permeability of the respective habitat (Butzer 1982; Crumley and Marquardt 1987; Marquardt and Crumley 1987; Tischendorf and Fahrig 2000a). Tischendorf and Fahrig (2000a) refer to the patch-scale index of landscape connectivity as a function of immigrations into the patch divided by the initial number of organisms within the patch (Tischendorf and Fahrig 2000a). The system connectivity behind this approach is basically determined by the scale of the individual resource patch or habitat and the scale of the distance between the respective patches. The movement that describes the exchange and migration between the patches, however, is subject to a variety of external stressors (e.g. hazards). Tischendorf and Fahrig (2000a, 2000b) describe three scenarios that an organism is exposed to during habitat variation: a higher mortality risk, adjusted movement patterns, and boundary crossing.

The concepts described above are strongly focused on spatial definitions of organisms and their ecological habitats. At first sight, the applicability in human-made landscape assemblages seems inappropriate. However, the integration of ecological approaches with landscape affordances (systemrelated) and spatial connectivity (resource-based) offers the possibility to understand landscapes not only through their spatial extent and physical human interaction but also as a situational expression of the immediate activity sphere in the moment of confrontation (Fig. 1).

\section{(Eco-)system resilience and human response cycle}

In 1984, Stuart Pimm defined a system to be stable, if the variables within this system all return to the initial equilibrium 
Fig. 1 Conceptualization model of the human response cycle considering situational, actual, and potential changes in landscape affordances during environmental transformation and innovation. Decision-making leads to sociocultural and environmental adaptation and increased (development) or decreased (collapse) system resilience. The flow of ecological processes and the availability of resource patches frame the movement of human activity ranges, organisms, and the development of human-made landscape configurations on various spatial and temporal scales

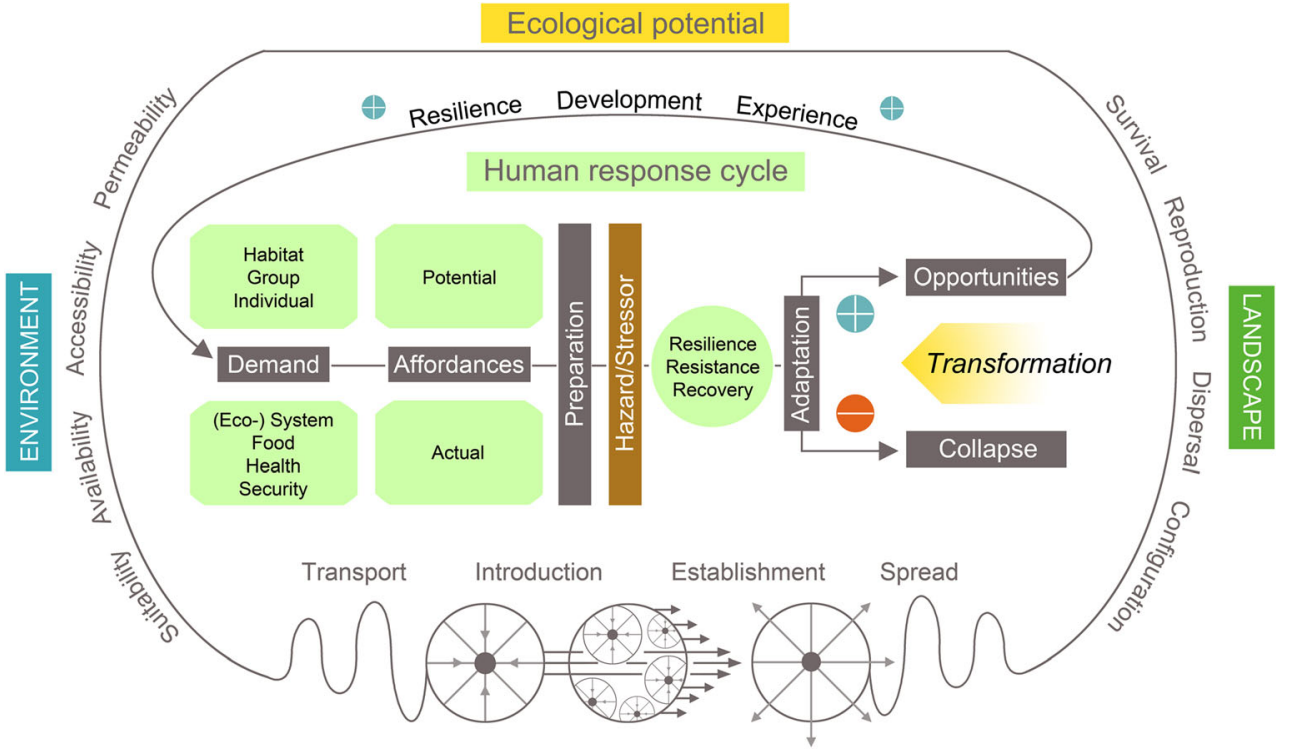

after being disturbed from their previous state (Pimm 1984). According to Holling and Gunderson (2002), this has met with considerable opposition during the past years (Holling and Gunderson 2002). A second definition emphasizes a system connectivity, which is far from any equilibrium, where the system's components are able to change their current state of behaviour in favour of another (Holling 1973; Holling and Gunderson 2002; Scheffer et al. 2002). Furthermore, a multi-actor behavioural approach has increasingly entered the discussion about resilience and its understanding in an ecological, economic, and sociocultural contextualization, integrating a processual component into the system's function and the adaptive cycle of human-environmental interaction (see Fig. 2) (Reggiani et al. 2002). The term resilience, originally introduced by C. S. Holling (1973) as a concept to understand an ecosystem's capability to persist perturbations
Fig. 2 System connectivity patterns among response, adaptive, and control cycles within a given ecosystem

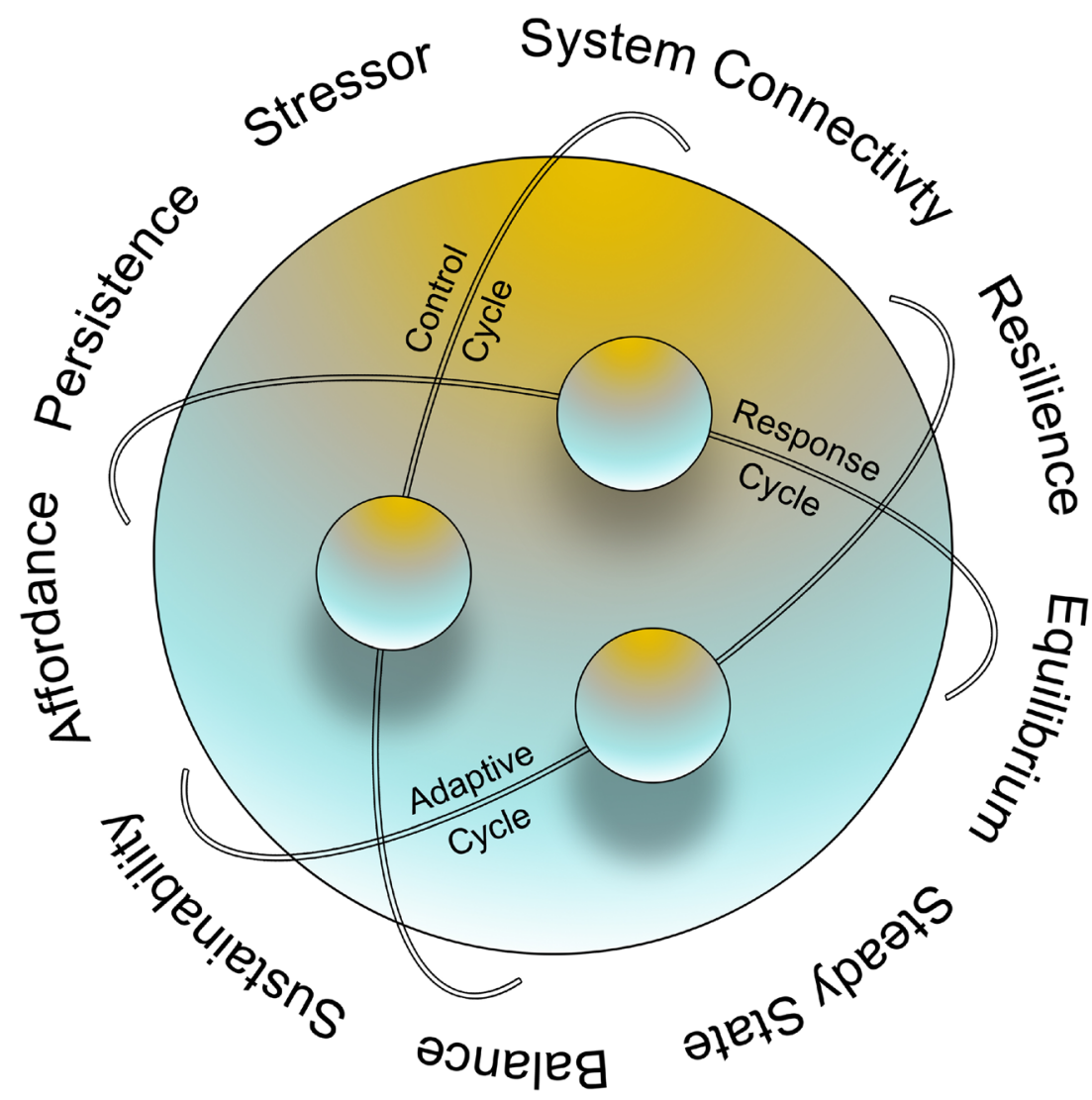


and alternative states of conditions (Folke et al. 2010; Holling 1973) and the "magnitude of disturbance that can be absorbed before the system changes its structure by changing the variables and processes that control behavior" (Holling and Gunderson 2002, p. 28), has been challenged considerably within the past decades and from a broad variety of disciplines (Berkes 2007; Bradtmöller et al. 2017; Torrence 2016). Recently, approaches to integrate archaeological data and climate and landcover change scenarios into resilience thinking and human response cycle theory have largely entered the stage. Among others, cultural heritage management and anticipation as well as sustainable agricultural land use and increased surface demand play a crucial role in the current debate about the preservation and in particular the transformation of performative and situational identities of archaeological monuments, cultural landscapes, and historical urban settings - and thus about the transmission of past human activity to contemporary human adaptation and behaviour (Fisher 2019; Holtorf 2018; Maran 2019). In this context, the question arises to which extent resilience is a necessary component in the (eco-)system's connectivity and balance if one considers nature-resilient systems as stable and not capable to transform and develop (Holling and Gunderson 2002). Cultural landscapes are considered a constant overlap of past, present, and future human decision-making processes and affordances, which form the specific performative and situational character of landscape development on both spatial and temporal scales (see Fig. 3). System stability would therefore not allow for development due to the fact that there are no potential system external or internal disturbances that challenge the state of the system. According to Scheffer et al. (2002), (eco-)systems can have multiple stable states for variable conditions, and disturbances may push these states beyond the limitations of the system's affordances, hence its options and potential contextualization (e.g. habitat boundaries and crossing, resource patch dispersal). The system will thus move to another stable state, in which it remains until further disturbances occur or the affordances of the system change (Scheffer et al. 2002).

Boundary crossing is closely connected to resource exploitation and the limitations of the local resource availability offered by the respective topography, geomorphology, and hydrology, and thus the particular landscape permeability (Butzer 1982). Resources cannot be considered unlimited, and for premodern groups, a sustainable interaction with the respective resource can hardly be supposed. Fundamental needs, such as firewood, decrease rapidly with the increasing size of the local community, which makes transport and storage cost-intensive and tedious. The link to scale-based considerations of human activity ranges is thus strongly connected to resource consumption and the carrying capacity of the immediate locale. These considerations are based to a large extent on theories of group persistence, innovation, and transformation (Fig. 1). The ecological system that has been transformed into a cultural landscape through the interaction of early hunter-gatherer groups and eventually through first farming activities during the Neolithic (Sielmann 1972) is nowadays perceived by modern humans as multidirectional palimpsests of past human behaviour. The system itself has not experienced changes, but rather is continuous with the same people covering most of the formerly populated and modified land surfaces. Reflecting on sustainable handling of resources and their local availability and scarcity is not an entirely novel consideration of modern mankind (Butzer 1982, pp. 286-289).

\section{Spatial connectivity: habitat, resource, and human behaviour}

Humans constantly modify their surroundings. Most of these modifications are ultimately visible in an immediate conflict between the perceiving individual and the perceived landscape. This intense physical relationship, however, is not necessarily required to actively transform the environment into cultural landscapes - a fact that has recently gained relevance. The irreversible transformation of ecosystems and the anthropogenic impact that triggers significant surface changes are processes that are constantly perceived by most individuals on earth. However, global change is not an entirely modern phenomenon. The human impact on the landscape can be traced back to early hunter-gatherer groups that intervened into and consciously interacted with their immediate habitats (Ellis et al. 2013; Morgan 2009). These interventions have led to ecological adaptations of both human and floral/faunal behaviour. Through the supraregional landscape connectivity of the respective resource patches, cross-border habitat changes happened, which affected neighbouring resource patches and thus transported cultural landscapes through the spread of human activity ranges.

Modern human behaviour cannot be considered completely different from the behaviour of past human groups. The increased impact on the earth's ecosystems and the confrontation with severe global climate change have emotionally dulled our self-reflection and our perception of the landscape. Like all other species, human (bio-)ecological behaviour depends on the limits and the extent of the environmental habitat. However, our modern activity ranges are pushed to the limits, and the vulnerability of large parts of the society has increased significantly. Even though we have reached a tipping point in the balance of ecosystems, the system that we perceive as natural and that we try to protect and manipulate is hardly untouched. Humans have transformed this planet into an entire cultural landscape where every ecological movement follows a predetermined path of either survival in distinct niches or rapid extinction. Nevertheless, there are two 


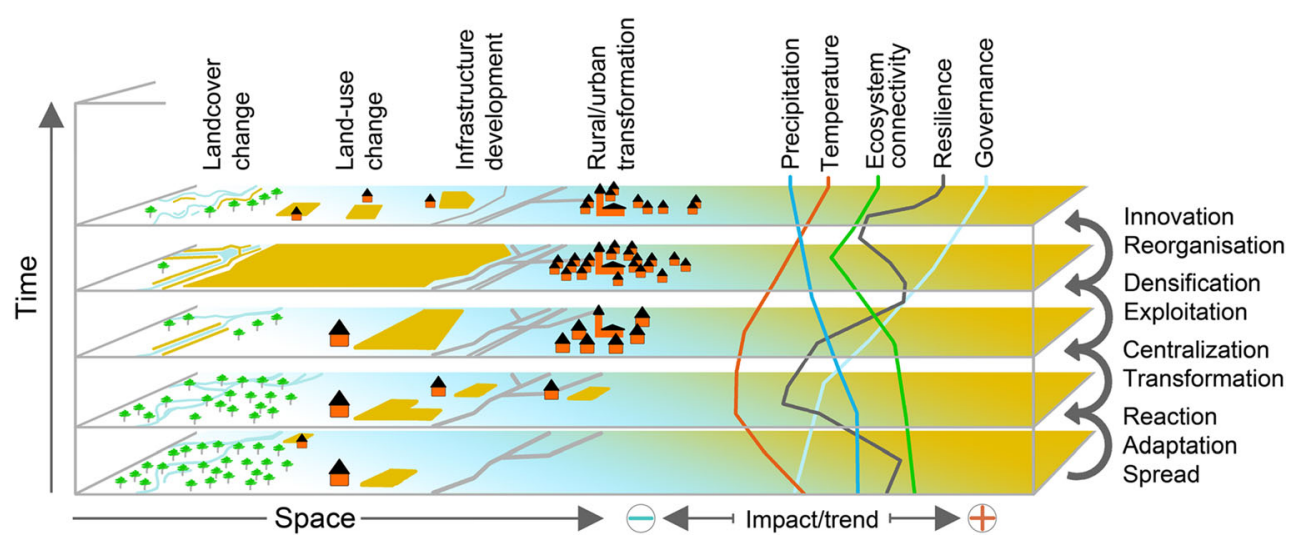

Fig. 3 A model of spatio-temporal dimensions of landscape development, transformation, and innovation. Landscapes are continuously transformed on the long-term scale (process). Short-term events occur frequently (e.g. climate instabilities), which have long-lasting effect on the landscape. A past landscape emerges that consists of the cultural and physical palimpsests of a variety of periods. The recent historical landcover change marks a threshold of intensified landscape modification and determines our modern perception of the immediate landscape as well as the (eco-)system resilience and the sociopolitical governance and decision-making important differences in the effect of past and present human behaviours: the perception of the global change and its speed.

It is important to notice that human behaviour is patterned but not always rational. That is a major point in the development of human-made landscapes. Areas that have a variety of resources or offer specific configurations are more attractive and more suitable than others. Consequently, landscape penetration intensifies with increased landscape affordanceseven though the resource exploitation entails a high costbenefit ratio. The problem emerges if we try to understand the behaviour of different societies, which placed their demands on the landscape and hence had spatially divergent activity ranges. As pointed out earlier, the modern landscape is a palimpsest of various cultural perceptions, ideas, and decisions that took place - and were placed - on the environment. In the following chapter, the ways in which these decisions could be isolated, tested, and visualized through modern techniques and multivariate datasets will be discussed.

\section{Temporal connectivity: event, process, and transformative cycle}

Reconstructing past environmental conditions using modern datasets is a critical approach (Dincauze 2000). Modern data is heavily biased not only by past environmental variability but also by the conceptual framework of our current society (Kempf 2020). Certain landscape perspectives appear to be a product of long-lasting natural development. Considered individually, these perspectives are rather the product of recent landcover transformations and do not represent accumulated settings. To understand the behaviour of landscapes in a spatio-temporal perspective, many different scales need to be considered. All these scales are inevitably linked to each other in the functional landscape connectivity.
Cultural imprints of past societies accumulate in the process of surface adaptation to the respective needs and demands of the population, which was interacting with its landscape at a specific moment in time (Hodder 2016). However, there are no static environmental and sociocultural systems. Short-term events such as volcanic eruptions or sociopolitical crises led to rapid changes in the ecosystem or to transformation and technological innovation of the local social hierarchy (Brandes 2005; Büntgen et al. 2016). Both temporal perspectives take place at the same time, but their consequences are perceived differently because rapid effects on the landscape are much more directly experienced. The immediate transformation of the individual's landscape affordances contributes to future decision-making about resource management, land use strategies, and settlement location choice - hence, rapid impacts lead to rapid transformation, whereas process-oriented adaptation triggers long-term development (Fig. 3).

Furthermore, human population dynamics are not linear (Diachenko and Zubrow 2015; Fernández-López de Pablo et al. 2019; Verhagen et al. 2014). Modern demographic changes put increasing pressure on the ecosystem (Henderson and Loreau 2019; Nguyen and Liou 2019). Consequently, the temporal scales of modern, historical, and prehistorical landcover need to be distinguished in any model that aims to reconstruct potential premodern surface developments. Figure 3 sketches the twofold character of process and event. Both can be considered to happen at the same time, just like rapid climate change is triggered by long-term ecosystem drawbacks. However, past environmental transformation is perceived rather on the long-term axis. Recent historical landscapes, on the other hand, are still considered to be actively linked to the conception of modern society - through images, paintings, traditions, and written sources. Modern landscapes are thus much more connected to recent landscapes, which influence the discussion about landscapes as identities and 
homeland ("Heimat") — a term that has critical connotations in the German language (Kühne 2019; Kühne and Weber 2019).

\section{Concerns, discussions, and future perspectives}

Event and process, landscape, and ecosystem functionalities are subject to a large variety of scientific research approaches. Among other, digital spatial and quantitative methods allow for pattern recognition in point-data distribution - a common data source in archaeology. This section discusses potential directions in landscape archaeology and offers a new approach to understand the human-landscape interaction. A supraregional case study that takes up on these considerations has recently been published by the author of this article (Kempf 2020).

\section{Landscape affordances: from ecology to human-made landscape assemblages}

According to Carl Knappett, "the affordance of an object is neither solely an independent property of the object itself, nor is it exclusively an intentional state within the mind of the person engaging with it, but a relational property shared between object and agent" (Knappett 2004, p. 46). In his 2004 paper, Knappett sees the engagement of an agent and an object as a dynamic and situational relationship that takes place in the environment/moment of the cognitive and/or physical interaction (Gibson 1986; Knappett 2004; Stoffregen 2003; Withagen et al. 2012). Arguing that variables in the moment of perception always have a temporal component, the directional perception of meaning forms the main requirement to apply the concept of affordances. Non-directional perceptions would not allow for intuitive acting because every moment would be characterized by the constant cognitive processing of perceived environmental agency data. Direct perception allows the individual to rapidly sample and process information that produces a mental map, which in turn forms the narrative structures of the landscape.

Although this article states that there is no agency in the landscape, and environmental attributes situated in environmental space do not contain meaning, direct perception of environmental data by an individual is one of the main requirements in the development of landscapes. Based on David Webster (1999), the relationship between affordances and landscapes can be cut into two pieces: low-order invariants denote the individual elements of a landscape. High-order invariants summarize these elements and generate potentially available/not available or usable/not usable surfaces that are offered to an individual (Webster 1999). However, it would further be useful to add another layer to the potential and actual affordances through including the dynamic conditions of the low-order invariants (Gillings 2007). Mere physical variables are throughout a product of feedbacks and interrelations of variables that are located close to each other in the environmental network. Low-order invariants can be seen as variables without a specific temporal and/or spatial character. The transfer of a variable from one stage (low-order) to another (high-order) is a constant process. Once entering another level in the system, the element is activated and transfers its energy to the next environmental particle in the new surroundings. Activation and de-activation of ecological processes are constant parameters of environmental development (Stoffregen 2000). The flow of ecological processes is in turn subject to the determinants of accessibility and availability of ecological habitats. In an ecological sense, these habitats are only of interest if they are achievable and available in an economic cost-benefit relation.

The threshold that allows a population to overcome the limitations of their habitat can be described spatially (e.g. overpopulation-system collapse-migration/extinction). In a model, this means consideration of the system's increased conservation costs (energy expenditure) and local vulnerability with the potential costs of restructuring (population vulnerability, resilience, adaptation costs). The actual vulnerability of an ecological system is thus controlled by the constant potential affordances which are built by the accumulation of at least two low-order variables. Although the potential affordances are not materially tangible, their presence materializes in the constant adaptation, preparation, reaction, and transformation of their immediate environment to past and potential future events. While affordances may not be immediately comprehensible to non-participants of the system, we are able to detect and visualize their baseline (accumulative low-order variables) and their consequences (adaptation strategies, habitat loss, re-orientation). Very basically speaking, this means that people gain information from the experience of other people (Gramsch 1996; Scarantino 2003). In a geoarchaeological context, this enables the possibility of interpolating affordances from multivariate landscape analyses (Kempf 2019, 2020).

\section{The transformation of the premodern landscape}

Landscape development is multidirectional in space and time. Decisions and choices that took place in the past landscape have transformed the present appearance of the world. Recent decisions about how particular parts of the earth will be used in the future influence our present landscape categorization. To summarize, all (human) presence is a transformation, and transformation of (A) leads to transformation of (B). This theory is supported by the concept of functional landscape connectivity, which enables the movement of organisms and the consequent development of landscape through the utilization of resource patches. It is important to notice that 
landscapes are not considered resources. However, landscapes contain resources. These resources determine the direction of human movement and consequently sociocultural development. A very descriptive example is the archaeological record of Roman mining activities in Europe and particularly in south-western Germany, which have entailed massive soil erosion processes and the accumulation of thick colluvial layers (Durali-Mueller et al. 2007; Fernández-Lozano et al. 2019; Mäckel et al. 2002; Mäckel et al. 2003; Mighall et al. 2017). The sediment input has not only altered the Roman land surface but also further influenced riverbed development and biodiversity. Small rivulets were channelized (Schwarz 2006), which disrupted species movement. The military occupation and the fortifications along the river Rhine involved a decentralized supply of livestock and people through local crop cultivation and extensive agricultural utilization (Weaverdyck 2019). New species were introduced (Livarda 2011), which spread in the favourable climatic conditions of the Upper Rhine Valley (Vandorpe and Jacomet 2011) - even after the Roman occupation. This example illustrates that landscape development is not a linear transformation of the surface but rather a product of multidirectional and multitemporal feedbacks of human decisions, affordances, and the availability of resources.

\section{Fables of the reconstruction: the bias in the data}

Modelling landscape affordances and past environmental prerequisites can still be considered an unsolved issue in landscape archaeology. Understanding the variability of a study site and its environmental feedbacks seems to be the key to set up a multivariate affordance model that aims to explain the patterned structures of the archaeological record. However, these patterns are subject to multiple biases that mostly lie in the unstructured and unrepresentative nature of the archaeological datasets (Cowley 2016; Knappett 2004; van Leusen 1996; van Leusen 2002).

As pointed out by the author for the Upper Rhine Valley, various environmental parameters and modern surface transformations bias the distribution and the perception of the archaeological record (Kempf 2020). In most cases, the actual bias is a composition of interdependencies of natural preconditions (e.g. drainage potential, river course) and anthropogenic reactions to them (Cowley 2016). The strong modern surface modifications make it particularly difficult to approach a potential premodern environmental surface. Without the blank sheet (or the concept of "nature"), there is hardly any potential reconstruction of landscape affordances that can be related to a specific culture. Accordingly, that precludes this approach to understanding the impact of this culture on their immediate landscape.

Critical conditions and environmental tipping points in sociocultural systems can only be recorded after their occurrence. That of course is one of the key elements of archaeological research, which is built on the material remains of collapsed societies. But to what extent is our modern archaeological distribution a reaction of past societies to premodern environmental conditions and how did they perceive their environment? Every archaeologically attested culture perceives their landscape as a remodelled construct of their predecessor's cultural landscape, and there is no landscape without human perception.

In this article, landscape affordance is not seen as the perception of purely physical resources but rather as the personal needs of individuals acting in their immediate environment. It has been argued that affordances cannot be seen as material properties in the landscape that can be physically perceived and consequently recorded (Gillings 2007; Webster 1999). This becomes particularly clear once the research reaches the digital level. It is rapidly glossed over that Gibson and Ingold had less in mind the modelling of archaeological records in relation to the environment than the sociological aspects of the propositional character of the landscape in relation to its organisms (Llobera 2012; Lock and Pouncett 2017). Quantitative methods in archaeology to detect interactions of humans are inevitably linked to visualizations of spatial patterns of archaeological material. And these are subject to cartographic standards, to digitally processed geodata, and thus to the danger of environmental determinism (Hodder 2016).

\section{Spatial patterns of the archaeological record: a modern past?}

Simple distribution maps of archaeological data are useless. They produce dehumanized patterns in artificial space (Butzer 1982; Sielmann 1972). The strength of GIS in archaeology is its diversity (Conolly and Lake 2006). The process behind the application of GIS, or digital modelling in general, is not meant to stand opposed to the interpretation of human patterns, but rather to complement and extend the approaches of a comprehensive and modern landscape archaeology (Gillings et al. 2020; Llobera 2012). Just like in any other science, uncertainties are a fundamental property of progress and research development, and archaeological data particularly can easily be confused with absolute data. However, it is the current state of archaeological research that is used to model spatial behaviour of past societies. In this context, the maps of modern landscape suitability models can be used to identify continuously used areas of intense human activity. On the other hand, they can also be used to estimate the impact of modern landcover change on the (modern) archaeological distribution and thus to engage in methodological source criticism. However, it has been pointed out recently by Verhagen and Whitley (2020) that the models are only as good as the data and the theories behind them - and modern land use further influences our perception of the distribution of archaeological finds in the landscape (van Leusen 2002; Verhagen and 
Whitley 2020). There can be several reasons for this: first, it is possible that the study area has experienced continuous utilization and settlement continuity. Consequently, the archaeological sites are located where the most suitable environmental conditions can be found. This would suggest a very stable ecological and environmental system and a likewise static human behaviour in the landscape. The other possibility is that the data are biased by the modern intensified surface transformation, the many excavations, field surveys, and the general interest in archaeology. The most likely would be a combination of both, the high suitability of the region, a continuous population, and a modern bias to the data.

\section{Conclusion}

David Cowley is critically asking whether our archaeological data are a representative reflection of past activity or the product of modern land use (Cowley 2016). He could have also critically asked whether our landscape is a representative image of past human activity or a product of modern landcover transformation. Either way, human activity ranges are dynamic and multilayered adaptations to environmental configurations and local landscape affordances. Modern surfaces thus represent resource assemblages of various perceptions, ideas, and decisions placed on the individual landscape. However, the system that underlies resource connectivity patterns and that ultimately forms the landscape is controlled by several short-term and long-term environmental processes, which are decisive for the human categorization of potential habitat or resource patches. To trace the patterns of past human behaviour, this spatio-temporal environmental variability needs to be detected, isolated, and interpreted in terms of ecological feedbacks and sociocultural reactions. The application of GISbased modern datasets, the integration of remote sensing techniques, and the consequent inclusion of archaeological data have proven to be an increasingly substantial method to understand premodern and modern landscape development.

Human activity ranges are not continuously equal. A variety of cultural and social groups have placed different demands on their landscape — on different sociocultural or socioeconomical scales. That has led to the sedimentation of various cultural layers and the heterogeneous utilization intensity of the landscape. Certainly, particular areas of the landscape have experienced more intense resource exploitation than others - mostly due to their increased affordances such as the actual material resources, the strategic locale, agricultural suitability, or the low settlement site vulnerability. These spatial patterns allow archaeologists to determine the cultural behaviour of groups that best fits their environmental preconditions.

In this context, one major problem is the dynamic composition of the landscape that follows no clear boundaries and is constantly remodelled by experiences, decisions, and choices of the individuals. The spatial analysis of archaeological sources such as settlement or burial ground distributions provides a potential way to access these compositions. Quantitative research allows the detection of patterns in relation to topography, geology, or the hydrological system of the contemporary society. However, it must be stressed that neither archaeologists nor environmental scientists are capable of entirely reconstructing past human behaviour. First, the available data are either incomplete or heavily biased by modern surface transformations. Finally, the modern perception of the landscape is a product of a variety of past landscape palimpsests, which includes cultural imprints on the (very) long-term scale. Understanding human patterns would consequently demand the analysis of all cultural periods at all temporal scales - a strongly optimistic challenge.

As recently stressed by the author, the available data is highly biased by the construction activities of modern society (Kempf 2020). This has produced rich archaeological information. However, the spatial information content of this data is primarily controlled by the local authorities, the modern pull factor of urban and rural agglomerations, and the technical standards of the respective cultural heritage departments. That makes it almost impossible to evaluate site location parameters and to set up a predictive model for potential archaeological risk maps - one of the major goals of cultural heritage management. Isolating the bias (and the noise) in the data is a big challenge of modern landscape archaeology and future cultural heritage protection.

The combination of the methodological approach presented in this paper and the multivariate model (Kempf 2020) is one potential step towards a comprehensive interpretation of past human behaviour. It must be pointed out that the interdisciplinary character of archaeological material research, (natural) scientific methods, quantitative statistics, and digital modelling demands a broadly specialized knowledge of ecological feedbacks and links in the socioenvironmental systems. However, spatial analysis and multivariate modelling can pave the way towards an equally valued interdisciplinary research-beyond the two cultures.

Acknowledgements I would like to thank three anonymous reviewers for their productive comments that fostered the structure behind this article. I am furthermore very grateful to Eli Weaverdyck (Freiburg) who proofread this manuscript and added invaluable comments. Finally, I would like to thank the editorial board of AASC and particularly Mareike Stahlschmidt for their constructive advices.

Funding information Open Access funding provided by Projekt DEAL.

Open Access This article is licensed under a Creative Commons Attribution 4.0 International License, which permits use, sharing, adaptation, distribution and reproduction in any medium or format, as long as you give appropriate credit to the original author(s) and the source, provide a link to the Creative Commons licence, and indicate if changes were made. The images or other third party material in this article are included in the article's Creative Commons licence, unless indicated otherwise in a 
credit line to the material. If material is not included in the article's Creative Commons licence and your intended use is not permitted by statutory regulation or exceeds the permitted use, you will need to obtain permission directly from the copyright holder. To view a copy of this licence, visit http://creativecommons.org/licenses/by/4.0/.

\section{References}

Alexander RJ (2009) Framing discourse on the environment: a critical discourse approach. In: Routledge critical studies in discourse, vol 1. Routledge, New York (Accessed: 23 December 2019)

Baguette $\mathrm{M}$ et al (2013) Individual dispersal, landscape connectivity and ecological networks. Biol Rev Camb Philos Soc 88(2):310-326. https://doi.org/10.1111/brv.12000

Berkes F (2007) Understanding uncertainty and reducing vulnerability: lessons from resilience thinking. Nat Hazards 41(2):283-295. https://doi.org/10.1007/s11069-006-9036-7

Bradtmöller M, Grimm S, Riel-Salvatore J (2017) Resilience theory in archaeological practice-an annotated review. Quat Int 446:3-16. https://doi.org/10.1016/j.quaint.2016.10.002

Brandes W (2005) Die Pest in Byzanz nach dem Tode Justinians (565) bis 1453. In: Meier M (ed) Pest: Die Geschichte eines Menschheitstraumas. Klett-Cotta, Stuttgart, pp 201-224

Bruineberg J, Chemero A, Rietveld E (2019) General ecological information supports engagement with affordances for 'higher' cognition. Synthese 196(12):5231-5251. https://doi.org/10.1007/ s11229-018-1716-9

Büntgen $U$ et al (2016) Cooling and societal change during the Late Antique Little Ice Age from 536 to around 660 AD. Nat Geosci 9(3):231-236. https://doi.org/10.1038/ngeo2652

Butzer KW (1982) Archaeology as human ecology. Cambridge University Press, Cambridge

Chemero A (2003) An outline of a theory of affordances. Ecol Psychol 15(2):181-195 (Accessed: 18 December 2019)

Conolly J, Lake M (2006) Geographical information systems in archaeology. In: Cambridge manuals in archaeology. Cambridge Univ. Press, Cambridge

Cowley DC (2016) What do the patterns mean? Archaeological distributions and bias in survey data. In: Forte M, Campana S (eds) Digital methods and Remote Sensing in Archaeology. Springer, Cham, pp $147-170$

Crumley CL (2016) Historical ecology: integrated thinking at multiple temporal and spatial scales. In: Hornborg A, Crumley CL (eds) The world system and the Earth system: Global socioenvironmental change and sustainability since the Neolithic. Routledge, London, pp 15-28

Crumley CL, Marquardt WH (eds) (1987) Regional dynamics: Burgundian landscapes in historical perspective. Acad. Pr, San Diego

Crumley CL, Marquardt WH (1990) Landscape: a unifying concept in regional analysis. In: Allen KM, Green SW, Zubrow EBW (eds) Interpreting space: GIS and archaeology, Applications of geographic information systems. Taylor \& Francis, London, pp 73-79

Cushman SA et al (2010) The gradient paradigm: a conceptual and analytical framework for landscape ecology. In: Cushman SA, Huettmann F (eds) Spatial Complexity, Informatics, and Wildlife Conservation. Tokyo, Springer-Verlag Tokyo, pp 83-108

Diachenko A, Zubrow EBW (2015) Stabilization points in carrying capacity: population growth and migrations. J Neolithic Archaeol 17: 1-15 (Accessed: 19 January 2020)

Dincauze DF (2000) Environmental archaeology: principles and practice. Cambridge Univ. Press, Cambridge
Durali-Mueller S et al (2007) Roman lead mining in Germany: its origin and development through time deduced from lead isotope provenance studies. J Archaeol Sci 34(10):1555-1567. https://doi.org/ 10.1016/j.jas.2006.11.009

Ellis EC et al (2013) Used planet: a global history. Proc Natl Acad Sci U S A 110(20):7978-7985. https://doi.org/10.1073/pnas.1217241110

Ellis EC (2015) Ecology in an anthropogenic biosphere. Ecol Monogr 85(3):287-331 (Accessed: 23 December 2019)

Fazey I et al (2010) Adaptation strategies for reducing vulnerability to future environmental change. Front Ecol Environ 8(8):414-422. https://doi.org/10.1890/080215

Fernández-López de Pablo J et al (2019) Palaeodemographic modelling supports a population bottleneck during the Pleistocene-Holocene transition in Iberia. Nat Commun 10(1):1872. https://doi.org/10. 1038/s41467-019-09833-3

Fernández-Lozano J et al (2019) Gold-bearing Plio-Quaternary deposits: insights from airborne LiDAR technology into the landscape evolution during the early Roman mining works in north-west Spain. J Archaeol Sci Rep 24:843-855. https://doi.org/10.1016/j.jasrep. 2019.03.001

Fisher C (2019) Archaeology for sustainable agriculture. J Archaeol Res 83(3):801. https://doi.org/10.1007/s10814-019-09138-5

Folke C et al (2010) Resilience thinking: integrating resilience, adaptability and transformability. Ecol Soc 15(4):20. http://www. ecologyandsociety.org/vol15/iss4/art20/. Accessed 15 Jul 2020

Furholt M (2018) Massive migrations? The impact of recent aDNA studies on our view of third millennium Europe. Eur J Archaeol 21(2): 159-191. https://doi.org/10.1017/eaa.2017.43

Gibson JJ (1979) The ecological approach to visual perception. Houghton Mifflin, Boston

Gibson JJ (1986) The ecological approach to visual perception. Erlbaum, Hillsdale

Gillings M (2007) The Ecsegfalva landscape: affordance and inhabitation. In: Whittle A (ed) The Early Neolithic on the Great Hungarian Plain: Investigations of the Körös culture site of Ecsegfalva 23, County Békés, vol 2. AKAPRINT Nyomdaipari Kft., Budapest, pp 31-46

Gillings M (2009) Visual affordance, landscape, and the megaliths of Alderney. Oxf J Archaeol 28(4):335-356 (Accessed: 29 June 2019)

Gillings M, Hacigüzeller P, Lock G (eds.) (2020) Archaeological spatial analysis: a methodological guide. Routledge, London/New York

Gobster PH et al (2007) The shared landscape: what does aesthetics have to do with ecology? Landsc Ecol 22(7):959-972. https://doi.org/10. 1007/s10980-007-9110-x

Gramsch A (1996) Landscape archaeology: of making and seeing. J Eur Archaeol 4:19-38

Greider T, Garkovich L (1994) Landscapes: the social construction of nature and the environment. Rural Sociol 59(1):1-24. https://doi. org/10.1111/j.1549-0831.1994.tb00519.x

Gurrutxaga M, Lozano PJ, del Barrio G (2010) GIS-based approach for incorporating the connectivity of ecological networks into regional planning. J Nat Conserv 18(4):318-326. https://doi.org/10.1016/j. jnc.2010.01.005

Hanson CA et al (2012) Beyond biogeographic patterns: processes shaping the microbial landscape. Nat Rev Microbiol 10(7):497-506. https://doi.org/10.1038/nrmicro2795

Harden CP (2012) Framing and reframing questions of humanenvironment interactions. Ann Assoc Am Geogr 102(4):737-747. https://doi.org/10.1080/00045608.2012.678035

Head L (2010) Cultural ecology: adaptation-retrofitting a concept? Prog Hum Geogr 34(2):234-242. https://doi.org/10.1177/ 0309132509338978

Henderson K, Loreau M (2019) An ecological theory of changing human population dynamics. People Nat 1(1):31-43. https://doi.org/10. $1002 /$ pan 3.8 
Heras-Escribano M, de Pinedo-García M (2017) Affordances and landscapes: overcoming the nature-culture dichotomy through niche construction theory. Front Psychol 8:2294. https://doi.org/10.3389/ fpsyg.2017.02294

Hodder I (2016) Studies in human-thing entanglement. Online publication: http://www.ian-hodder.com/books/studies-human-thingentanglement. Accessed 15 Jul 2020

Holling CS (1973) Resilience and stability of ecological systems. Annu Rev Ecol Syst 4(1):1-23. https://doi.org/10.1146/annurev.es.04. 110173.000245

Holling CS, Gunderson LH (2002) Resilience and adaptive cycles. In: Gunderson LH, Holling CS (eds) Panarchy: understanding transformations in human and natural systems. Island Press, Washington, DC, pp 25-62

Holtorf C (2018) Embracing change: how cultural resilience is increased through cultural heritage. World Archaeol 50(4):639-650. https:// doi.org/10.1080/00438243.2018.1510340

Ingold T (2000) The perception of the environment: essays on livelihood, dwelling and skill. Routledge, London

Jung M (2018) 'Das objektepistemologische Potential des Affordanzkonzeptes James Gibsons und seine Bedeutung als Grundlage von ,Objektbiographien'. Methodologische Anmerkungen und exemplarische Fallstudie', in Hilgert, M., Hofmann, K. and Simon, H. (eds.) Objektepistemologien. Zur Vermessung eines transdisziplinären Forschungsraums. (Berlin Studies of the Ancient World, 59). Berlin: Pro Business digital printing, pp. 135-178

Kempf M (2019) The application of GIS and satellite imagery in archaeological land-use reconstruction: a predictive model? J Archaeol Sci Rep 25:116-128. https://doi.org/10.1016/j.jasrep.2019.03.035

Kempf M (2020) Modelling multivariate landscape affordances and functional ecosystem connectivity in landscape archaeology. Archaeol Anthropol Sci 12. https://doi.org/10.1007/s12520-020-01127-w

Kent M (2007) Biogeography and landscape ecology. Prog Phys Geogr Earth Environ 31(3):345-355. https://doi.org/10.1177/ 0309133307079059

Knappett C (2004) The affordances of things: a post-Gibsonian perspective on the relationality of mind and matter. In: DeMarrais E, Gosden C, Renfrew C (eds) Rethinking materiality: the engagement of mind with the material world. (McDonald Institute monographs). McDonald Institute for Archaeological Research, Cambridge, pp $43-51$

Kühne O (2019) Phänomenologische Landschaftsforschung. In: Kühne $\mathrm{O}$ et al (eds) Handbuch Landschaft. (RaumFragen: Stadt - Region Landschaft). Springer Fachmedien Wiesbaden, Wiesbaden, pp 135144 (Accessed: 19 January 2020)

Kühne O, Weber F (2019) Landschaft und Heimat - argumentative Verknüpfungen durch Bürgerinitiativen im Kontext des Stromnetz- und des Windkraftausbaus. In: Hülz M, Kühne O, Weber F (eds) Heimat: Ein vielfältiges Konstrukt. (RaumFragen: Stadt - Region - Landschaft). Springer Fachmedien Wiesbaden, Wiesbaden, pp 163-178 (Accessed: 19 January 2020)

Kupfer JA (1995) Landscape ecology and biogeography. Prog Phys Geogr 19(1):18-34 (Accessed: 3 January 2020)

Kupfer JA (2012) Landscape ecology and biogeography. Prog Phys Geogr Earth Environ 36(3):400-420. https://doi.org/10.1177/ 0309133312439594

Livarda A (2011) Spicing up life in Northwestern Europe: exotic food plant imports in the Roman and medieval world. Veg Hist Archaeobotany 20(2):143-164. https://doi.org/10.1007/s00334010-0273-Z

Llobera M (1996) Exploring the topography of mind: GIS, social space and archaeology. Antiquity 70(269):612-622. https://doi.org/10. 1017/S0003598X00083745

Llobera M (2012) Life on a pixel: challenges in the development of digital methods within an "interpretive" landscape archaeology framework.
J Archaeol Method Theory 19(4):495-509. https://doi.org/10.1007/ s10816-012-9139-2

Lock G, Pouncett J (2017) Spatial thinking in archaeology: is GIS the answer? J Archaeol Sci 84:129-135. https://doi.org/10.1016/j.jas. 2017.06.002

Lomolino MV, Pijanowski BC, Gasc A (2015) The silence of biogeography. J Biogeogr 42(7):1187-1196. https://doi.org/10.1111/jbi. 12525

Loveland KA (1991) Social affordances and interaction II: autism and the affordances of the human environment. Ecol Psychol 3(2):99-119. https://doi.org/10.1207/s15326969eco0302_3

Mäckel R et al (2002) Environmental changes and human impact on the relief development in the Upper Rhine valley and Black Forest (south-west Germany) during the Holocene. Zeitsch Geomorphol $128: 31-45$

Mäckel R, Schneider R, Seidel J (2003) Anthropogenic impact on the landscape of southern Badenia (Germany) during the Holocenedocumented by colluvial and alluvial sediments. Archaeometry 45(3):487-501 (Accessed: 5 June 2019)

Maran J (2019) Not 'cultures', but culture! The need for a transcultural perspective in archaeology. In: Abu-Er-Rub L et al (eds) Engaging transculturality: concepts, key terms, case studies. Routledge, Abingdon, pp 52-64

Marquardt WH, Crumley CL (1987) Theoretical issues in the analysis of spatial patterning. In: Crumley CL, Marquardt WH (eds) Regional Dynamics: Burgundian landscapes in historical perspective. Acad. Pr, San Diego, pp 1-18

McGarigal K, Cushman SA (2009) The gradient concept of landscape structure. In: Moss MR (ed) Wiens, J.A. Cambridge University Press, Issues and Perspectives in Landscape Ecology, pp 112-119

Meyer WJ, Crumley CL (2011) Historical ecology. In: Moore T, Armada X-L (eds) Atlantic Europe in the first millennium BC: Crossing the divide. Oxford University Press, Oxford, pp 109-134 (Accessed: 24 June 2020)

Mighall T et al (2017) Did prehistoric and Roman mining and metallurgy have a significant impact on vegetation? J Archaeol Sci Rep 11: 613-625. https://doi.org/10.1016/j.jasrep.2016.12.021

Morgan C (2009) Climate change, uncertainty and prehistoric huntergatherer mobility. J Anthropol Archaeol 28(4):382-396. https:// doi.org/10.1016/j.jaa.2009.07.004

Müller J (2005) 'Soziale Grenzen und Zeichensysteme in prähistorischen Gesellschaften', in Kienlin, T.L. (ed.) Die Dinge als Zeichen: Kulturelles Wissen und materielle Kultur ; internationale Fachtagung an der Johann-Wolfgang-Goethe-Universität Frankfurt am Main, 3.-5. April 2003. (Universitätsforschungen zur prähistorischen Archäologie, 127). Bonn: Habelt, pp. 255-261

Nguyen K-A, Liou Y-A (2019) Global mapping of eco-environmental vulnerability from human and nature disturbances. Sci Total Environ 664:995-1004. https://doi.org/10.1016/j.scitotenv.2019.01.407

O'Farrell PJ, Anderson PML (2010) Sustainable multifunctional landscapes: a review to implementation. Curr Opin Environ Sustain 2(1-2):59-65. https://doi.org/10.1016/j.cosust.2010.02.005

Pimm SL (1984) The complexity and stability of ecosystems. Nature 307: 321-326 (Accessed: 17 June 2020)

Reggiani A, de Graaf T, Nijkamp P (2002) Resilience: an evolutionary approach to spatial economic systems. Netw Spat Econ 2:211-229 (Accessed: 17 June 2020)

Rietveld E, Kiverstein J (2014) A rich landscape of affordances. Ecol Psychol 26(4):325-352. https://doi.org/10.1080/10407413.2014. 958035

Scarantino A (2003) Affordances explained. Philos Sci 70(5):949-961. https://doi.org/10.1086/377380

Schaich H, Bieling C, Plieninger T (2010) Linking ecosystem services with cultural landscape research. GAIA 19(4):269-277 (Accessed: 26 April 2019) 
Scheffer M et al (2002) Dynamic interaction of societies and ecosystemslinking theories from ecology, economy, and sociology. In: Gunderson LH, Holling CS (eds) Panarchy: understanding transformations in human and natural systems. Island Press, Washington, DC, pp 195-239

Schwarz, P.A. (2006) 'Gewässerkorrektionen in römischer Zeit', in Hüster Plogmann, H. (ed.) Fisch und Fischer aus zwei Jahrtausenden: Eine fischereiwirtschaftliche Zeitreise durch die Nordwestschweiz. (Forschungen in Augst, 39). Augst: Römermuseum Augst, pp. 51-61

Sielmann, B. (1972) 'Die frühneolithische Besiedlung Mitteleuropas', in Schwabedissen, H. (ed.) Die Anfänge des Neolithikums vom Orient bis Nordeuropa Westliches Mitteleuropa: bearb. von Jens Lüning. Köln: Böhlau, pp. 1-65

Stedman RC (2003) Is it really just a social construction? The contribution of the physical environment to sense of place. Soc Nat Resour 16(8):671-685. https://doi.org/10.1080/08941920309189

Stoffregen TA (2000) Affordances and events. Ecol Psychol 12(1):1-28. https://doi.org/10.1207/S15326969ECO1201_1

Stoffregen TA (2003) Affordances as properties of the animalenvironment system. Ecol Psychol 15(2):115-134. https://doi.org/ $10.1207 /$ S15326969ECO1502_2

Taylor K (2012) Landscape and meaning: context for a global discourse on cultural landscape values. In: Taylor K, Lennon J (eds) Managing cultural landscapes, Key issues in cultural heritage. Routledge, London, pp 21-44

Taylor PD et al (1993) Connectivity is a vital element of landscape structure. Oikos 68(3):571-573 (Accessed: 26 April 2019)

Taylor PD, Fahrig L, With KA (2006) Landscape connectivity: a return to the basics. In: Crooks KR, Sanjayan M (eds) Connectivity Conservation. Cambridge University Press, Cambridge, pp 29-43

Tischendorf L, Fahrig L (2000a) How should we measure landscape connectivity? Landsc Ecol 15:633-641 (Accessed: 24 June 2020)

Tischendorf L, Fahrig L (2000b) On the usage and measurement of landscape connectivity. Oikos 90:7-19 (Accessed: 3 January 2020)

Torrence R (2016) Social resilience and long-term adaptation to volcanic disasters: the archaeology of continuity and innovation in the Willaumez Peninsula, Papua New Guinea. Quat Int 394:6-16. https://doi.org/10.1016/j.quaint.2014.04.029

van Leusen M (2002) Pattern to process: methodological investigations into the formation and interpretation of spatial patterns in archaeological landscapes: PhD Thesis. Groningen Institute for Archaeology, University Groningen van Leusen PM (1996) Unbiasing the archaeological record. Archeol Calcolat 7:129-136

Vandorpe P, Jacomet S (2011) 'Remains of burnt vegetable offerings in the temple area of Roman Oedenburg (Biesheim-Kunheim, HautRhin, Alsace): first results', in Wiethold, J. (ed.) Carpologia: Articles réunis à la mémoire de Karen Lundsröm-Baudais ; actes des Rencontres d'Archéobotanique organisé par Bibracte, Centre Archéologique Européen et le Centre de Recherches Archéologiques de la Vallée de l'Oise, 9-12 juin 2005, Glux-enGlenne. (Collection Bibracte, 20). Glux-en-Glenne: Bibracte, 87-10

Verhagen P, Joyce J, Groenhuizen M (2014) 'Modelling the dynamics of demography in the Dutch Roman limes zone', Multi-, inter- and transdisciplinary research in Landscape Archaeology, Landscape Archaeology Conference, 2014: VU E-Publishing. https://doi.org/ 10.5463/lac.2014.62

Verhagen P, Whitley TG (2020) Predictive spatial modelling. In: Gillings M, Hacigüzeller P, Lock G (eds) Archaeological spatial analysis: A methodological guide, pp 231-246

Watson DM et al (2017) Monitoring ecological consequences of efforts to restore landscape-scale connectivity. Biol Conserv 206:201-209. https://doi.org/10.1016/j.biocon.2016.12.032

Weaverdyck EJS (2019) The role of forts in the local market system in the Lower Rhine: towards a method of multiple hypothesis testing through comparative modelling. In: Verhagen P, Joyce J, Groenhuijzen MR (eds) Finding the Limits of the Limes. Springer International Publishing, Cham, pp 165-190

Webster DS (1999) The concept of affordance and GIS: a note on Llobera (1996). Antiquity 73(282):915-917. https://doi.org/10.1017/ S0003598X00065698

Withagen $\mathrm{R}$ et al (2012) Affordances can invite behavior: reconsidering the relationship between affordances and agency. New Ideas Psychol 30(2):250-258. https://doi.org/10.1016/j.newideapsych. 2011.12.003

Withagen R, Araújo D, de Poel HJ (2017) Inviting affordances and agency. New Ideas Psychol 45:11-18. https://doi.org/10.1016/j. newideapsych.2016.12.002

Withagen R, Chemero A (2009) Naturalizing perception. Theory Psychol 19(3):363-389. https://doi.org/10.1177/0959354309104159

Publisher's note Springer Nature remains neutral with regard to jurisdictional claims in published maps and institutional affiliations. 